\title{
Convenient food made of extruded adzuki bean attenuates inflammation and improves glycemic control in patients with type 2 diabetes: a randomized controlled trial
}

This article was published in the following Dove Press journal:

Therapeutics and Clinical Risk Management

\section{Yanping Liu',* \\ Qiyan Wangl,* \\ Shanshan $\mathrm{Li}^{\prime}$ \\ Yanfen Yue ${ }^{2}$ \\ Yuling $\mathrm{Ma}^{3}$ \\ Guixing Ren ${ }^{3}$}

'Nutrition Department, Chinese Academy of Medical Sciences, Peking Union Medical College, Peking Union Medical College Hospital, Beijing,

China; ${ }^{2}$ Nutrition Department, Pinggu Hospital of Traditional Chinese Medicine, Beijing, China; ${ }^{3}$ Institute of Crop Sciences, Chinese Academy of Agricultural Sciences, Beijing, China

*These authors contributed equally to this work
Correspondence: Guixing Ren Institute of Crop Sciences, Chinese Academy of Agricultural Sciences, No 80 Xueyuan South Road, Haidian District, Beijing 10008I, China

Tel $+8610621 \mid 5596$

Fax +861062156596

Email renguixing@caas.cn
Objective: Extrusion is a widely used food processing technology. The aim of this study was to investigate the effects of extruded adzuki bean convenient food (EABCF) on glycemic and inflammation control in type 2 diabetes mellitus (T2DM) patients.

Patients and methods: In a randomized controlled trial, 120 T2DM patients were randomly assigned to a control diet group (the low glycemic index [LGI] group, assigned the traditional diabetic low glycemic index diet) or an intervention group (the EABCF group, assigned daily consumption of EABCF). Diet information and blood samples were collected at baseline and after a 4-week intervention. After excluding exogenous insulin users, a subgroup analysis based on baseline fasting insulin (FINS) levels was conducted, and Homeostasis Model Assessment (HOMA) was the target indicator.

Results: A total of 106 patients completed the trial, and 89 participants were included in the subgroup analysis. After the intervention, glycemic control improved in both groups compared to baseline, but the difference was not statistically significant $(p>0.05)$. However, the EABCF group showed decreased inflammation with significantly lower tumor necrosis factor alpha (TNF- $\alpha$ ) level compared to the control group (adjusted $p<0.01$ ). There was also a slight increase in the interleukin-6 (IL-6) level in the EABCF group (adjusted $p=0.004$ ). Moreover, the subgroup analysis found that, after 4 weeks, a diet consisting of EABCF increased insulin secretion to normal levels in the group with hypoinsulinism (baseline FINS $<5.2 \mathrm{mU} / \mathrm{L}$ ). However, the difference only showed a trend toward statistical significance $(0.05<p=0.079<0.1)$.

Conclusion: EABCF had a similar hypoglycemic effect as the traditional diabetic LGI diet and showed a greater inhibitory effect on inflammation in T2DM patients. However, further clinical studies are needed to explore the underlying mechanism.

Keywords: processed food, dietary intervention, insulin resistance, interleukin-6, high sensitive C reactive protein, tumor necrosis factor alpha, randomized controlled trial

\section{Introduction}

The incidence of type 2 diabetes mellitus (T2DM), a severe metabolic disorder, has been increasing in recent years, and the incidence is estimated to increase from $4 \%$ to $\sim 5.4 \%$ by $2025 .{ }^{1}$ A low glycemic index (LGI) diet, in which the glycemic index of food is $\leq 55$, has been regarded as the optimal diet for diabetic patients. The key point of this diet is to choose appropriate staple foods. Traditional LGI grains include buckwheat, oats, barley and wheat bran. ${ }^{2}$ Along with such grains, some starchy legumes, such as red adzuki bean $(\mathrm{GI}=26)$, are also a staple in the diabetic 
diet. In addition to having a LGI, adzuki has been found to have hypoglycemic properties. Former case series studies performed by the Institute of Crop Sciences of the Chinese Academy of Agricultural Sciences (CAAS) have indicated that extruded adzuki bean protein $(10 \mathrm{mg} / \mathrm{mL})$ has an inhibitory effect on $\alpha$-glucosidase in vitro (with an inhibition rate of $60.44 \%) .{ }^{3}$ In addition, the fasting blood glucose (FBG) levels of type 2 diabetic mice significantly decreased after they were given fodder enriched with $1 \%$ or $2 \%$ extruded adzuki bean protein. ${ }^{4}$

The adzuki bean, also known as the small red bean, originated in China and has a long history of cultivation. The bean has a stable production and is mainly distributed in northern China, with a large proportion exported to Southeast Asian countries such as Korea and Japan. ${ }^{5}$ From the nutritional standpoint, the small red bean, credited as "the red pearl in grain," is a starchy legume rich in a variety of minerals such as iron, calcium, phosphorus and potassium. Furthermore, it contains large amounts of bioactive molecules such as flavones, phytosterols, saponins and natural pigment. Modern pharmacological studies have shown that the small red bean has anti-inflammatory and antibacterial properties affecting blood pressure and blood lipid levels, which are likely due to its abundance of flavonoids and saponins. ${ }^{6}$ The flavonoids in the bean are mainly epicatechin, catechin, rutin and Yang-mei rutinoside, with the average content of each being $0.76-1.31 \mathrm{mg} / \mathrm{g}{ }^{7}$ In vitro experiments have shown that these flavonoids have anti-inflammatory properties, which can inhibit proinflammatory cytokines, including cyclooxygenase-2, lipoxygenase, inducible NO synthase, nuclear factor $\mathrm{kB}(\mathrm{NF}-\mathrm{kB})$ and activator protein-1 (AP-1). ${ }^{8}$ Other studies have indicated that flavonoids can also weaken the expression of various inflammatory cytokines in macrophages, T cells and peripheral blood mononuclear cells, including TNF- $\alpha$ and interleukins. ${ }^{7}$ However, the correlation between the anti-inflammatory effect and hypoglycemic effect of red adzuki bean has seldom been reported.

The extrusion process plays an important role in refining coarse grains, improving the taste of grains, eliminating undesirable factors and increasing protein digestibility. It has been applied widely to the manufacture of convenient foods owing to its simple technique, low energy consumption and low cost. ${ }^{9}$

To solve problems such as the unappealing taste of the coarse staple food and the long cooking time, three kinds of extruded adzuki bean convenient food (EABCF), including vermicelli, instant powder and hard candy, have been developed by CAAS. However, the effectiveness of these products requires validation using clinical trials. We hypothesize that compared to the traditional diabetic LGI diet, EABCF is more effective in controlling glucose levels and inflammation in T2DM patients. To test this hypothesis, a parallel, randomized, open-label, controlled trial was designed to evaluate the changes in glucose metabolism indicators and inflammatory markers among T2DM patients following a 4-week EABCF intervention compared to a traditional LGI diet.

\section{Patients and methods Participants}

From January to February 2016, type 2 diabetic patients were recruited from the endocrinology clinic of the Pinggu Hospital of Traditional Chinese Medicine (Beijing, China). The inclusion criteria were as follows: 1) diagnosis of T2DM according to the Type 2 Diabetes ADA Diagnosis Criteria; ${ }^{10}$ 2) age between 30 and 65 years; 3) latest labtexting $\mathrm{FBG} \geq 6.1 \mathrm{mmol} / \mathrm{L}$ or glycosylated hemoglobin $(\mathrm{HbA} 1 \mathrm{c})>6.5 ; 4)$ volunteers with normal cognition, word fluency, mobility and literacy; and 5) informed and voluntary participation. The exclusion criteria were as follows: 1) T2DM patients with serious complications such as diabetic ketoacidosis or hyperglycemic hyperosmolar syndrome; 2) patients with acute cardiovascular disease; 3) patients with malignancy, infection, active inflammation, diseases of the immune system or diseases of the hematopoietic system; 4) T2DM patients with severe liver or kidney dysfunction; and 5) pregnant or lactating women. The subject's medications or other clinical interventions were required to remain unchanged during the intervention period; otherwise, the subject was excluded. The sample size estimation was based on the study of the prevalence and control of diabetes in Chinese adults by Wang, ${ }^{11}$ which showed that at least 50 people for each group are needed to observe a change in fasting blood sugar levels. Based on a $20 \%$ rate of missing data, this study was estimated to require 120 participants. In total, 216 patients responded to the recruiting advertisement, 182 of which met the inclusion criteria. Out form the 182 candidates, 120 patients were selected using the random number table. Next, 120 selected patients were randomly assigned to the control group (LGI group) or the intervention group (EABCF group), with 60 subjects in each group. During the 4-week intervention, 14 subjects withdrew, and the remaining 106 subjects completed the study, resulting in 51 subjects in the LGI group and 55 in the EABCF group (Figure 1).

\section{Study design}

A parallel, randomized, open-label, controlled, 4-week dietary intervention trial was designed to compare the 


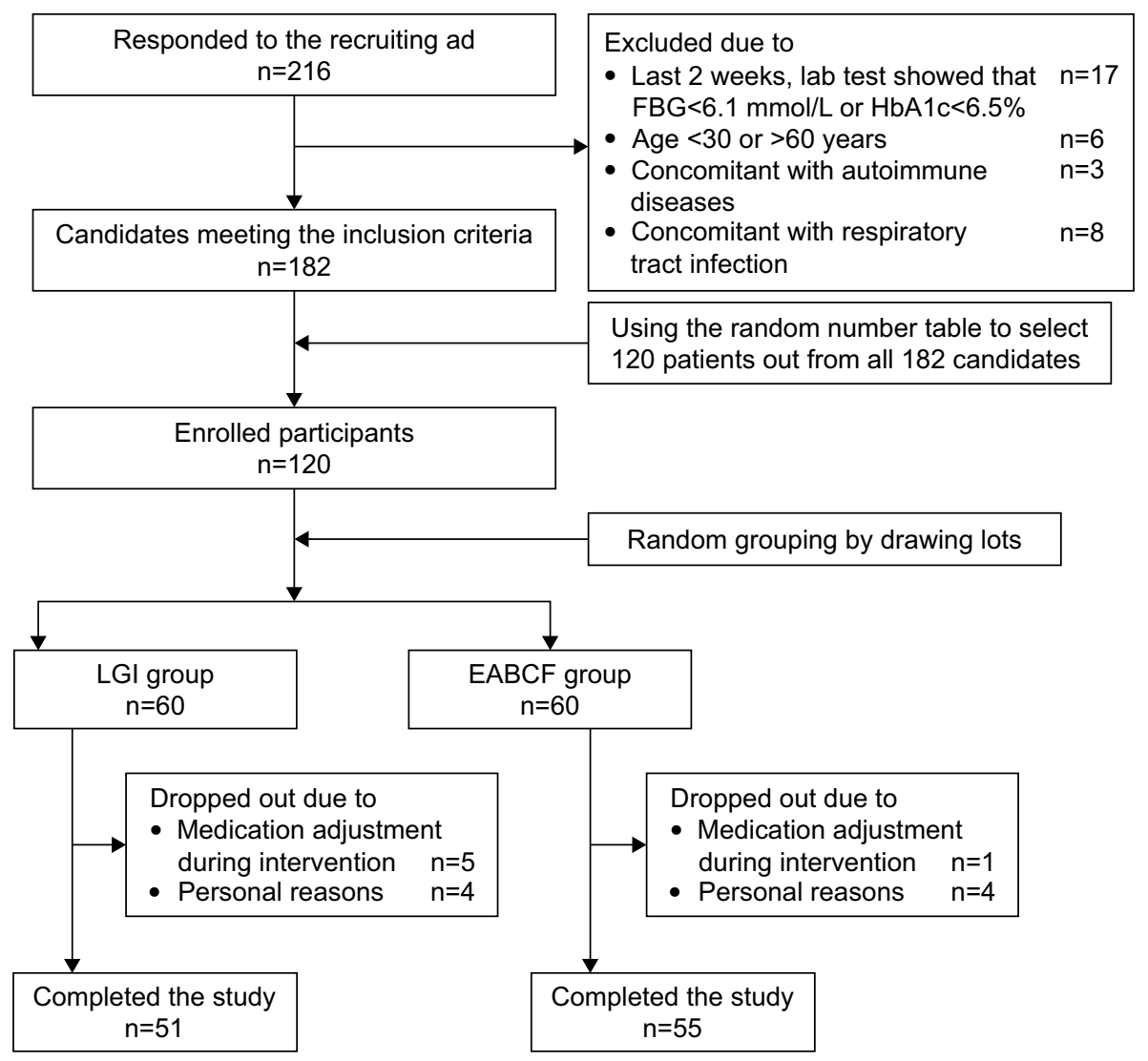

Figure I Flow chart for subject recruitment, enrollment and group assignment.

Abbreviations: $\mathrm{EABCF}$, extruded adzuki bean convenient food; FBG, fasting blood glucose; HbAlc, glycosylated hemoglobin; LGl, low glycemic index.

effects of a traditional diabetic LGI diet (control) and a diet consisting of the EABCF (intervention) on glycemic control and inflammation in patients with T2DM. All participants underwent a training course conducted by 4 trained dietician assistants prior to the start of the intervention. The training course covered basic knowledge of dietary management of diabetes mellitus (DM), including the glycemic index of foods, food exchanges, and raw-mature conversions, and the instructions for completing the daily dietary diary. During the first face-to-face outpatient consultation, every participant received a personalized dietary regimen with details of daily calories and dietary intake requirements from different foods. The recipes were formulated by 3 professional dieticians according to the Dietary Guidelines for Chinese Residents (2016) $^{12}$ and the Chinese Guidelines for Nutritional Treatment for Diabetes (2013). ${ }^{13}$ Subjects were required to follow different instructions regarding the dietary intake of grains depending on their group assignment. The control group was to consume traditional LGI grains, such as buckwheat, oats, barley, wheat bran and starchy beans (excluding red adzuki beans), whereas the EABCF group was to consume the $\mathrm{EABCF}$ vermicelli with the same calories for one meal (preferably breakfast). Subjects in the EABCF group were also required to consume 2 bags of EABCF instant powder before each of the three meals and chew the EABCF hard candies, two at a time, three times a day.

Participants in the EABCF group were asked to return the uneaten vermicelli, instant powder and hard candy each week, and the researchers tracked the consumption of the intervention food. All participants were required to record their daily diet in a dietary diary in a consistent format, and the diaries were analyzed at the end of the study. Every subject was equipped with a food scale to ensure the accuracy of the daily diet. During the 4-week intervention period, both groups of subjects were asked to maintain their exercise habits and medication regimens and periodically provide the researchers with feedback regarding their health. The researchers would carry out weekly telephone or face interview to assess whether the subjects were continually suitable for the study.

\section{Intervention characteristics}

There were three kinds of modified convenient food made of extruded red adzuki bean for the intervention diet, including vermicelli, instant powder and hard candy. The extrusion process was developed by CAAS, and the Shandong Kangmei 
Pharmaceutical Co., Ltd (Shandong, China) produced the test samples. The nutritional components, specifications and directions for the three types of intervention foods are listed in Table 1.

\section{Questionnaire design}

The questionnaires involved in this study were the Patient's Basic Information Form and the Dietary Diary Record Sheet. The Basic Information Questionnaire, designed by the present authors, asked about demographic characteristics, diabetes history, family history, medication history and diabetic complications, along with information regarding other comorbidities and drug usage. The questionnaire was immediately collected after completion at the first visit, while the dietary records were collected and reviewed by the dietician assistants every week. Four weeks later, two researchers extracted the data from the dietary diary into the Nutrition Clinic Consultation Management System in parallel, a diet information analysis software.

\section{Study indices}

Before and after the intervention, calibrated instruments were used to measure the height, body weight, waist and hipline of each subject using standard methods. All parameters were measured twice, and the average values were recorded. The body mass index (BMI) was calculated according to the formula BMI=weight $(\mathrm{kg}) /$ height $^{2}\left(\mathrm{~m}^{2}\right)$, and the waist-to-hip ratio (WHR) was calculated using the formula $\mathrm{WHR}=$ waist circumference $(\mathrm{cm}) /$ hip circumference $(\mathrm{cm})$. The systolic and diastolic blood pressure were measured on the right arm using the Omron HEM-7000 electronic blood pressure monitor (Dalian, China). Before and after the intervention, all subjects underwent venous blood collection in the morning after fasting for at least 8 hours to determine levels of FBG, HbA1c, glycated albumin (GA), fasting insulin (FINS), high sensitive $\mathrm{C}$ reactive protein (hs-CRP), tumor necrosis factor alpha (TNF- $\alpha$ ) and interleukin-6 (IL-6). The blood samples were sent to the clinical laboratory center of Peking Union Medical College Hospital (PUMCH). FBG was measured by the Olympus AU5400 automatic analyzer (Olympus Corporation, Tokyo, Japan) using commercial kits from Wako Pure Chemical Industries Ltd (Osaka, Japan). The level of HbA1c was analyzed by a glycosylated glucose meter (Bio-Rad Laboratories Inc., Hercules, CA, USA) based on high-performance liquid chromatography (HPLC). GA was tested by enzymology using the Japan Lucina GA-L kit from Asahi Kasei Corporation (Tokyo, Japan). The level of FINS was analyzed by ADVIA Centaur CP Immunoassay System (Siemens AG, Berlin and Munich, Germany). The detection of hs-CRP using the immune transmission ratio was conducted by the Beckman Coulter LX-20 automatic biochemical analyzer (Beckman Coulter Inc., Brea, CA, USA). TNF- $\alpha$ and IL-6 levels were detected by enzyme linked immunosorbent assay (ELISA) using a Siemens Immulite 1000 (Siemens AG). Other formulas involved were as follows: the insulin resistance index (Homeostasis Model Assessment $($ HOMA $)-I R)=F B G(\mathrm{mmol} / \mathrm{L}) \times \mathrm{FINS}(\mu \mathrm{U} / \mathrm{mL}) / 22.5$; insulin sensitivity index $(\mathrm{HOMA}-\mathrm{IS})=22.5 /[\mathrm{FBG}(\mathrm{mmol} / \mathrm{L}) \times$ FINS $(\mu \mathrm{U} / \mathrm{mL})]$; and pancreatic beta-cell function index $(\mathrm{HOMA}-\beta)=20 \times \mathrm{FINS}(\mu \mathrm{U} / \mathrm{mL}) /[\mathrm{FPG}(\mathrm{mmol} / \mathrm{L})-3.5](\%)$.

Table I Nutritional components, specifications and directions for the extruded red adzuki bean convenient food

\begin{tabular}{|c|c|c|c|}
\hline & Vermicelli & Instant powder & Hard candy \\
\hline \multicolumn{4}{|c|}{ Nutritional information (per 100 g/NRV\%) } \\
\hline Energy & $\mathrm{I}, 467 \mathrm{KJ} / \mathrm{I} 7 \%$ & $\mathrm{I}, 528 \mathrm{KJ} / \mathrm{I} 8 \%$ & $\mathrm{I}, 586 \mathrm{KJ} / \mathrm{I} \% \%$ \\
\hline Protein & $16.5 \mathrm{~g} / 28 \%$ & $16.3 \mathrm{~g} / 27 \%$ & $6.4 \mathrm{~g} / 11 \%$ \\
\hline Fat & $1.02 \mathrm{~g} / 2 \%$ & $\mathrm{l} . \mathrm{g} / 2 \%$ & I.I g/2\% \\
\hline Carbohydrate & $65.1 \mathrm{~g} / 22 \%$ & $67.6 \mathrm{~g} / 22 \%$ & $81.4 \mathrm{~g} / 27 \%$ \\
\hline Soluble dietary fiber & $1.6 \mathrm{~g} / 6 \%$ & - & - \\
\hline Insoluble dietary fiber & $3.75 \mathrm{~g} / 15 \%$ & - & - \\
\hline Sodium & $314 \mathrm{mg} / 16 \%$ & $<5 \mathrm{mg} / 0 \%$ & $<5 \mathrm{mg} / 0 \%$ \\
\hline \multicolumn{4}{|l|}{ Specifications } \\
\hline & $100 \mathrm{~g} / \mathrm{bag} \times 5$ bags/package & $8 \mathrm{~g} / \mathrm{bag} \times 30 \mathrm{bags} / \mathrm{box}$ & 2 g/tablet $\times 24$ tablets/box \\
\hline \multicolumn{4}{|c|}{ Active ingredient (adzuki bean extract) } \\
\hline & $\geq 10 \mathrm{~g} / \mathrm{bag}$ & $\geq 5 \mathrm{~g} / \mathrm{bag}$ & $\geq 0.8 \mathrm{~g} /$ tablet \\
\hline \multicolumn{4}{|l|}{ Direction } \\
\hline Minimum recommended intake & $50-75 \mathrm{~g} / \mathrm{d}$ & 48 g/d (2 bags $\times$ Tid $)$ & I 2 g/d (2 tablets $\times$ Tid $)$ \\
\hline Best consumption time & Breakfast & Pre-prandial & Snacks \\
\hline Administration & Boil for $10-15$ minutes & Dissolve using warm water & Chew \\
\hline
\end{tabular}

Note: "_" =undetected; $\mathrm{Tid}=$ three times a day.

Abbreviation: NRV, nutrient reference value. 


\section{Quality control}

The questionnaires and dietary diaries used in the study were created based on relevant references and repeated modifications by clinicians. The questionnaires and dietary diaries were handed out, collected and organized by a designated researcher. Any sheets with missing or false information were identified and immediately completed or corrected by calling the corresponding subjects. The data of these forms were independently entered by two researchers. The inputted data were confirmed by mutual inspection. All researchers and volunteers involved in this study were strictly trained to ensure scientific accuracy, strictness and consistency in the data collection. Blood test results were reported by the laboratory of PUMCH and directly imported into SPSS17.0. All blood samples for blood sugar detection were tested within 2 hours of collection, while the other tests were completed within 24 hours of blood collection. To minimize the dropout rate, all participants were informed of the potential significance of this study at the time of enrollment, and the researchers remained in contact with the participants throughout the study.

\section{Data analysis}

All data were analyzed by SPSS17.0. Continuous variables were expressed as mean $\pm \mathrm{SD}$. Continuous variables derived from the original data were expressed as mean and $95 \%$ CIs. Dichotomous variables were expressed as numbers with percentages (\%). For a non-normal distribution, the KruskalWallis $\mathrm{H}$ test was used to compare multiple independent samples. For normal distributions, the independent $t$-test was used for comparisons between groups, and the paired $t$-test was used for comparisons within groups. Analysis of covariance (ANCOVA) using a generalized linear model was performed to eliminate potential confounding factors, and the food intake variables were adjusted by gender, age, height and baseline weight; weight and BMI were automatically adjusted by gender and age. The FBG, HbAlc, GA, FINS, hs-CRP, TNF- $\alpha$ and IL- 6 values were adjusted by gender, age, baseline BMI and duration of diabetes. The naturally logarithmic values of FINS, HOMA-IR, HOMA-IS and HOMA- $\beta$ were used for subgroup analysis. Values of $p<0.05$ were considered statistically significant; if $0.05<p<0.1$, there was a trend toward statistical significance.

\section{Ethics approval and informed consent} This study was registered on ClinicalTrials.gov with the identification NCT02999867. The study protocol was approved by the Ethnic Committee of Peking Union Medical College Hospital, Chinese Academy of Medical Sciences (Unique Protocol ID: PUMCH-ZS-1048). All 120 participants were informed of the details of this study, and every participant provided written informed consent for this study.

\section{Results}

\section{Baseline characteristics}

A total of 120 patients with T2DM were enrolled in the study. After the 4-week intervention, 14 patients withdrew, and the remaining 106 patients completed the study (51 in the LGI group and 55 in the EABCF group) (Figure 1).

The sex ratio and the average age, height and baseline weight of the two groups were not significantly different $(p>0.05)$. The mean age of the 120 patients was 57.5 years, and nearly $70 \%$ of them had abdominal obesity. Abdominal obesity was defined as male waist circumference $\geq 90 \mathrm{~cm}$ or female waist circumference $\geq 80 \mathrm{~cm} .{ }^{14}$ The data from the questionnaires showed that there were no statistically significant differences in the history of diabetes, family history of diabetes, the use of antidiabetic drugs and the incidence of diabetic complications between the two groups $(p>0.05)$. The number of hypertensive patients in the EABCF group was two times that in the LGI group ( 30 cases vs 15 cases, $p=0.032$ ). The average value of systolic and diastolic blood pressures and the number of patients taking antihypertensive drugs were higher in the EABCF group; however, the differences were not statistically significant $(p>0.05)$. The incidence of dyslipidemia and the number of subjects using lipid-lowering agents were similar in the two groups $(p>0.05)$ (Table 2).

\section{Dietary assessment}

The Nutrition Clinic Consultation Management System (Zhending Health Technology Co Ltd, Shanghai, China) was used to assess the diet according to the diaries kept by the participants, and the statistics of nutrient intake were calculated automatically based on the Chinese Food Composition Table (2009) ${ }^{2}$ and the nutritional values of the intervention food (Table 1). To eliminate bias from confounding factors, the results were adjusted by gender, age, height and baseline weight using the ANCOVA generalized linear model. Before the intervention, the daily energy intake, the intake of the three nutrients and the energy supply ratio of the two groups were nearly the same, and there were no statistically significant differences between the two groups (adjusted $p>0.05$ ). The two groups had similar dietary fiber and fatty acid intake patterns (adjusted $p>0.05$ ). After the 4-week 
Table 2 Characteristics of the participants at baseline

\begin{tabular}{|c|c|c|c|}
\hline Characteristics & $\begin{array}{l}\text { LGI } \\
\text { group } \\
(n=5 I)\end{array}$ & $\begin{array}{l}\text { EABCF } \\
\text { group } \\
(n=55)\end{array}$ & $p$-value \\
\hline Male, n (\%) & $24(47.1)$ & $23(4 \mid .8)$ & 0.696 \\
\hline Age (years) & $57.4 \pm 8.8$ & $57.6 \pm 8.8$ & 0.912 \\
\hline Weight (kg) & $68.1 \pm 10.7$ & $70.2 \pm 10.2$ & 0.321 \\
\hline Height (cm) & $161.4 \pm 8.4$ & $160.8 \pm 6.9$ & 0.719 \\
\hline Abdominal obesity, ${ }^{\mathrm{a}}$ (\%) & $35(68.6)$ & $38(69.1)$ & 1.000 \\
\hline Duration of DM (years) & $9.1 \pm 6.5$ & $8.1 \pm 5.6$ & 0.358 \\
\hline Family history, n (\%) & $22(43.1)$ & $26(47.3)$ & 0.700 \\
\hline Diabetes medication use & & & 0.263 \\
\hline No diabetes medication, $\mathrm{n}(\%)$ & $14(27.5)$ & $9(16.4)$ & - \\
\hline Oral only, n (\%) & $30(58.8)$ & $36(65.5)$ & - \\
\hline Insulin only, n (\%) & $2(3.9)$ & $3(5.5)$ & - \\
\hline Oral and insulin, $\mathrm{n}(\%)$ & $5(9.8)$ & $7(12.7)$ & - \\
\hline Complication, n (\%) & II (2I.6) & $10(18.2)$ & 0.808 \\
\hline Systolic blood pressure $(\mathrm{mmHg})$ & $136.6 \pm 17.7$ & $141.3 \pm 17.6$ & 0.174 \\
\hline Diastolic blood pressure $(\mathrm{mmHg})$ & $76.9 \pm 10.2$ & $79.4 \pm 10.9$ & 0.221 \\
\hline Hypertension, ${ }^{b} \mathrm{n}(\%)$ & $15(29.4)$ & $30(54.5)$ & 0.032 \\
\hline Antihypertensive agents, n (\%) & $12(23.5)$ & $21(38.2)$ & 0.142 \\
\hline Dyslipidemia, ${ }^{c}$ n (\%) & $22(43.1)$ & $26(47.3)$ & 0.700 \\
\hline Lipid-lowering agents, n (\%) & II (2I.6) & $8(14.5)$ & 0.449 \\
\hline
\end{tabular}

Notes: Continuous variables are expressed as mean \pm standard deviation, and the difference between groups was tested by the independent $t$-test; dichotomous variables are expressed as numbers (percentage, $\mathrm{n}(\%)$ ), and the difference between groups was analyzed by a cross table. The difference was considered statistically significant if $p<0.05$. If $0.05<p<0$. I, there was a trend toward statistical significance. ${ }^{a} \mathrm{Abdominal}$ obesity was defined as male circumference $\geq 90 \mathrm{~cm}$ or female waist circumference $\geq 80 \mathrm{~cm}$. ${ }^{14}$ bThe diagnosis of hypertension was made according to the 7th Report of the Joint National Committee on Prevention, Detection, Evaluation, and Treatment of High Blood Pressure. ${ }^{15}$ The diagnosis of dyslipidemia was based on the American guidelines from the National Cholesterol Education Program Adult Treatment Panel III (ATP III)

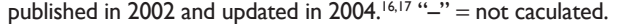

Abbreviations: EABCF, extruded adzuki bean convenient food; DM, diabetes mellitus; LGI, low glycemic index.

intervention, the fat intake decreased, and the energy supply ratio of fatty acids fell below $25 \%$ in both groups (adjusted $p>0.05$ ). Although the total intake of fat decreased, the ratio of fatty acid types remained unchanged (saturated: monounsaturated: polyunsaturated fatty acids equal to 2:1:1). The carbohydrate to energy ratio decreased below $60 \%(59 \%)$ after the 4-week intervention, while the ratio in the control group remained $>60 \%(61.32 \%)$. This difference between the groups trended to statistical significance $(0.05<p=0.066<0.1)$. After the EABCF intervention, the protein intake increased to nearly $60 \mathrm{~g}$ per day, which was a significantly higher than that in the LGI group $(59.85 \mathrm{~g}$ vs $55.09 \mathrm{~g} ; 0.05<p=0.055<0.1)$. On the other hand, at the end of the study, the protein to energy ratio in the $\mathrm{EABCF}$ group showed a marked increase to $17.34 \%$. This increase and the absolute value of protein intake were significantly higher than those in the control group (adjusted $p=0.042$ and 0.001 , respectively). In terms of dietary fiber intake, compared to baseline, the control group showed a more significantly decline $(p=0.048)$ (Table 3$)$.

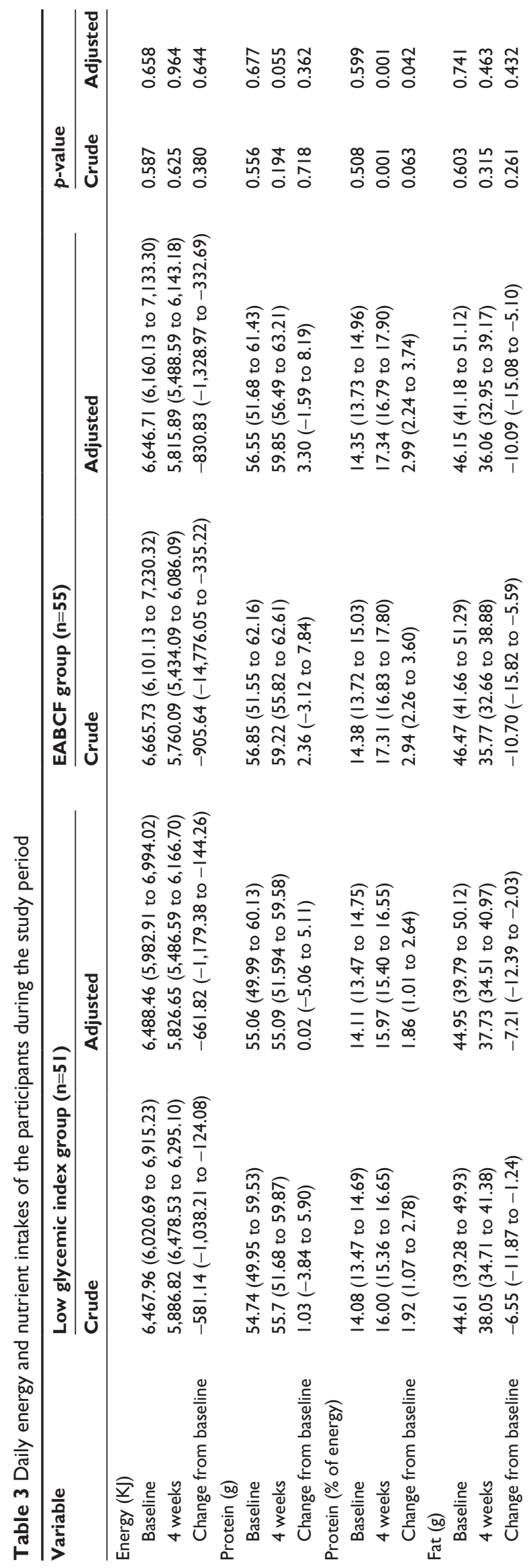




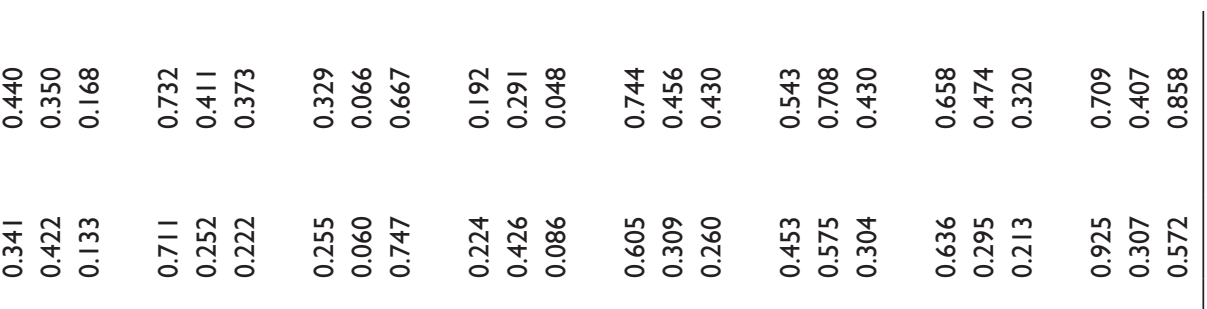

สิธิ์

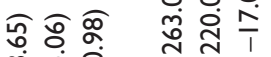

iे

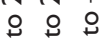

웅

8 \&

요

过定岤

đํ.

는

千.

离棉

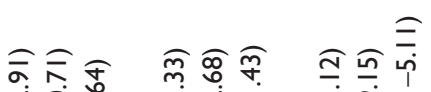

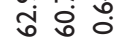

$\underline{\underline{m}} \underline{\mathrm{i}}$

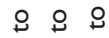

$\circ \circ \begin{gathered}0 \\ 0\end{gathered}$

ก. 용

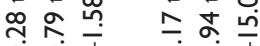

边迎过

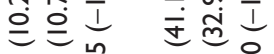

주요

ळ. 숭

붕 능응

กं

ठํำ

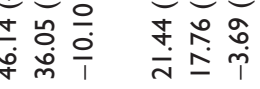

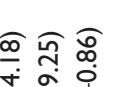

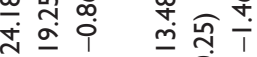

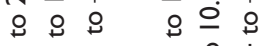

ㅇำ

$\underline{\infty} \underline{i}$

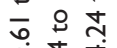

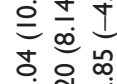

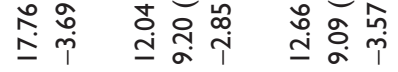

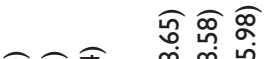

₹용 क्ष

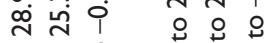

$\therefore \circ$

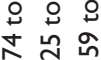

金品 年

क के

过完证

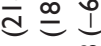

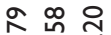

중

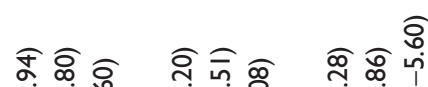

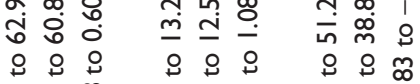

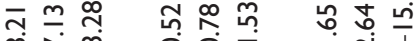

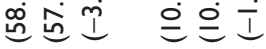

可

我

क्ष

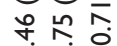

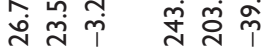

iी

f.

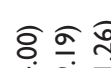

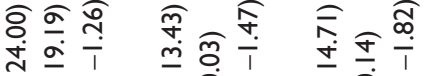

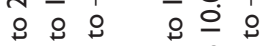

$\underline{m} \simeq$ น้

要它

กิ 웅

웅 웅

至产主

$\bar{N} \simeq$

-

कूष

कิำ

స

$\circ \%$

요음

$\circ \%$

$\bar{N} \alpha \bar{m}$

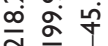

ป d

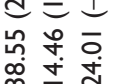

กิ

ㄷํㅇำ

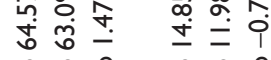

$\circ 28 \%$

ㅇำ

ㅇำ

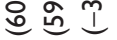

三은

ㅇำ

م.

공

สิ

ल ल I

นू

ㄷํำล

$\therefore$ 웅

กิ

E王

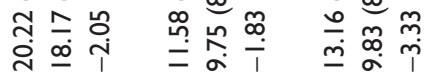

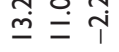

过命

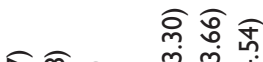

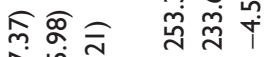

ㅊํㄴ 눈

$\circ \%$

동 웅

ฮู่

釷

$\circ$ 용

m

đ్త

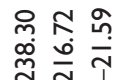

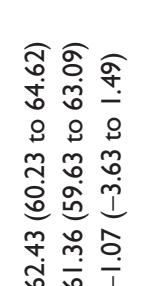

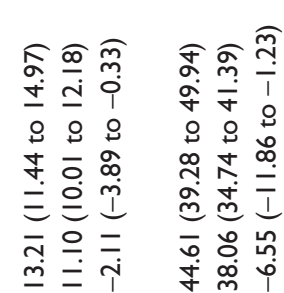

ㄱㅀㅇ

그

\&

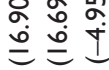

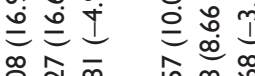

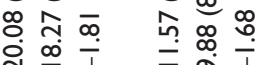

นิ่

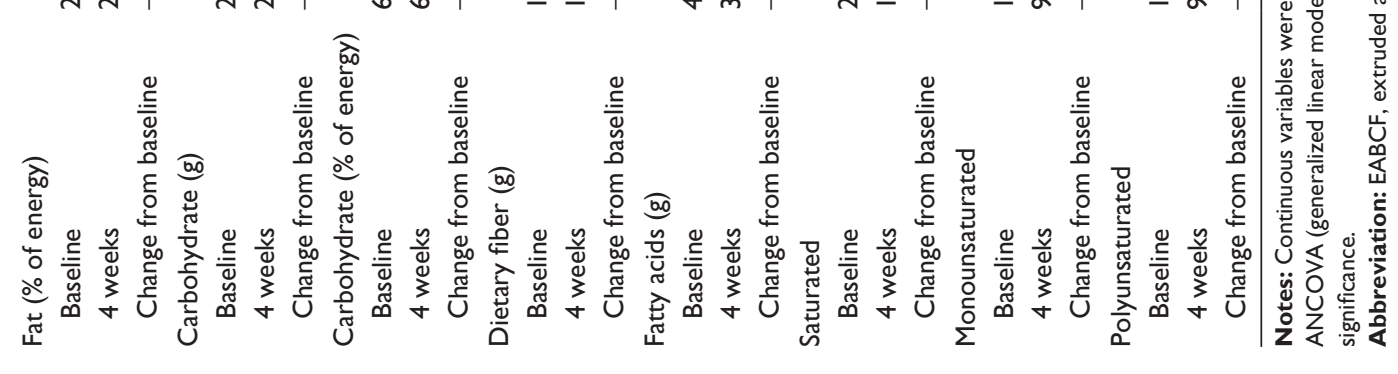




\section{Glycemic control and inflammatory status}

The ANCOVA generalized linear model was used to adjust for the possible bias of gender and age on weight and BMI. The adjusted mean weight and BMI indicated that most participants were overweight $\left(24 \leq \mathrm{BMI}<28 \mathrm{~kg} / \mathrm{m}^{2}\right)$ at the start of the study, and the average weight of the EABCF group was slightly higher than that of the LGI group. The BMI classification criteria are the standard obesity classification for Chinese residents. ${ }^{18}$ After the 4-week intervention, the weight of either group did not show obvious changes. Similarly, the four selected glycemic control indicators were similar between groups at baseline $(p>0.05)$, although the baseline levels for FBG, $\mathrm{HbA1c}$ and GA in the EABCF group were slightly higher than those in the LGI group and the level of FINS in the EABCF group was slightly lower than that in the LGI group. At the end of the study, all four indicators decreased in both groups; however, no statistically significant difference was found between groups (adjusted $p>0.05$ ). The $p$-value was calculated after adjusting for confounding factors including gender, age, history of diabetes and baseline BMI. In addition, it should be noted that at the end of the study, the level of FINS of one female participant in the EABCF group was not obtained due to laboratory error.

On the other hand, the changes in inflammatory markers were more marked. Three inflammatory factors were selected to monitor the inflammatory status of all participants before and after the intervention. The outcomes were adjusted by gender, age, history of diabetes and baseline BMI. Before the intervention, the EABCF group reflected a more severe inflammatory state, suggested by a significantly higher interleukin-6 (IL-6) level compared with the LGI group (adjusted $p=0.041$ ). After the 4-week intervention, the three indicators hs-CRP, TNF- $\alpha$ and interleukin-6 (IL-6) showed different trends. In the LGI group, the hs-CRP level decreased slightly, while the TNF- $\alpha$ and IL-6 levels increased markedly. Conversely, the TNF- $\alpha$ level decreased in the EABCF group and was significantly lower than that in the LGI group (adjusted $p<0.01$ ). Although the IL-6 levels increased in both groups compared to baseline, the LGI group showed a significantly greater increase than compared to the intervention group (adjusted $p=0.004$ ). At the end of the study, the IL-6 level in the EABCF group trended toward being statistically significantly lower than that in the LGI group (adjusted $0.05<p=0.051<0.1$ ) (Table 4 ).

\section{Subgroup analysis of HOMA models based on different levels of baseline FINS}

To investigate the association of inflammatory status with insulin resistance, insulin sensitivity and islet beta cell function, a subgroup analysis of HOMA indices based on different levels of baseline FINS was performed. Patients treated with exogenous insulin were excluded from this subgroup analysis. The two groups of subjects were each divided into three subgroups according to baseline FINS levels: the oversecretion group (FINS $\geq 17.2 \mathrm{mU} / \mathrm{L}$ ), the normal-secretion group (5.2 $\leq$ FINS $<17.2 \mathrm{mU} / \mathrm{L})$ and the inhibited-secretion group (FINS $<5.2 \mathrm{mU} / \mathrm{L}$ ). The standard reference for grouping was the normal range of FINS $(5.2-17.2 \mathrm{mU} / \mathrm{L})$ provided by the PUMCH laboratory. After excluding patients who use exogenous insulin, the remaining 89 subjects were included in the subgroup analysis, of whom 44 were in the LGI group and 45 were in the EABCF group. At the end of the trial, the FINS level of one female subject in the EABCF group was not available; therefore, her data were excluded from the subgroup analysis, ultimately leaving 44 subjects in the EABCF group. The researchers calculated HOMA-IR, HOMA-IS and HOMA- $\beta$ using the formulas mentioned in the methodology section. The values of FINS, HOMA-IR, HOMA-IS and HOMA- $\beta$ showed non-normal distributions. Thus, before the statistical analysis, natural logarithms were obtained to meet the normal distribution. Before the intervention, there was no significant difference in the baseline indices between the groups $(p>0.05)$. After the 4 weeks, the HOMA indicators showed different trends in the three subgroups. The trends in the insulin over-secretion and normal-secretion groups were similar: the FINS, HOMA-IR, and HOMA- $\beta$ values declined slightly from baseline and HOMA-IS increased slightly after the intervention in both groups. There were no significant differences between the groups $(p>0.05)$. Unlike these two groups, the trends observed in the inhibitedsecretion group was the opposite: the secretion of FINS increased in both groups, and the average level of FINS in the EABCF group was within the normal range of FINS $(5.2 \mathrm{mU} / \mathrm{L}<7.27 \mathrm{mU} / \mathrm{L}<17.2 \mathrm{mU} / \mathrm{L})$. The FINS value of the LGI group $(4.51 \mathrm{mU} / \mathrm{L}<5.2 \mathrm{mU} / \mathrm{L})$ was still abnormal. The difference in the FINS between the two groups had a trend toward statistical significance $(0.05<p=0.091<0.1)$. At baseline or 4 weeks later, the between-group differences in the logarithm of HOMA-IS, HOMA-IR and HOMA- $\beta$ were not statistically significant $(p>0.05)$ (Table 5).

\section{Discussion}

This study included 120 patients with type 2 diabetes, with 14 subjects withdrawing during the 4-week intervention, leaving 106 who completed the trial (51 in the LGI group and 55 in the EABCF group). The HOMA subgroup analysis included 89 participants who did not use exogenous insulin for glucose control. One FINS value was missing at the end 
Table 4 Changes in metabolic parameters of participants during the study period

\begin{tabular}{|c|c|c|c|c|c|c|}
\hline \multirow[t]{2}{*}{ Variable } & \multicolumn{2}{|l|}{ LGI group $(n=5 I)$} & \multicolumn{2}{|l|}{ EABCF group $(n=55)$} & \multicolumn{2}{|l|}{$\underline{p \text {-value }}$} \\
\hline & Crude & Adjusted & Crude & Adjusted & Crude & Adjusted \\
\hline \multicolumn{7}{|l|}{ Weight ${ }^{a}(k g)$} \\
\hline Baseline & $68.13 \pm 10.74$ & 67.89 (65.35 to 70.43$)$ & $70.16 \pm 10.20$ & 70.38 (67.94 to 72.83$)$ & 0.321 & 0.164 \\
\hline 4 weeks & $68.05 \pm 10.73$ & 67.82 (65.20 to 70.43$)$ & $70.17 \pm 10.42$ & 70.38 (67.87 to 72.90$)$ & 0.305 & 0.164 \\
\hline Change from baseline & $-0.08(-0.50$ to 0.34$)$ & $-0.07(-1.00$ to 0.86$)$ & 0.01 (-I.18 to I.19) & $0(-0.90$ to 0.90$)$ & 0.549 & 0.913 \\
\hline \multicolumn{7}{|l|}{$\mathrm{BMI}^{\mathrm{a}}\left(\mathrm{kg} / \mathrm{m}^{2}\right)$} \\
\hline Baseline & $26.1 \mathrm{I}(25.2 \mathrm{I}$ to $27.0 \mathrm{I})$ & 26.10 (25.25 to 26.96$)$ & 27.07 (26.23 to 27.90$)$ & 27.08 (26.25 to 27.90$)$ & 0.119 & 0.107 \\
\hline 4 weeks & 28.06 (24.20 to 26.93$)$ & $26.06(25.21$ to 26.91$)$ & 27.06 (26.22 to 27.91$)$ & 27.07 (26.25 to 27.89$)$ & 0.102 & 0.092 \\
\hline Change from baseline & $-0.04(-0.21$ to 0.12$)$ & $-0.04(-0.39$ to 0.31$)$ & $-0.01(-0.45$ to 0.45$)$ & $-0.01(-0.34$ to 0.34$)$ & 0.869 & 0.875 \\
\hline \multicolumn{7}{|l|}{$\mathrm{FBG}^{\mathrm{b}}(\mathrm{mmol} / \mathrm{L})$} \\
\hline Baseline & $8.85 \pm 2.65$ & 8.80 (8.06 to 9.53$)$ & $9.05 \pm 2.85$ & 9.11 (8.40 to 9.81$)$ & 0.705 & 0.554 \\
\hline 4 weeks & $8.29 \pm 2.48$ & 8.22 (7.27 to 8.89$)$ & $8.50 \pm 2.34$ & 8.56 (7.93 to 9.19$)$ & 0.643 & 0.468 \\
\hline Change from baseline & $-0.56(-1.07$ to -0.06$)$ & $-0.57(-1.06$ to -0.08$)$ & $-0.55(-1.01$ to -0.09$)$ & $-0.54(-1.01$ to -0.07$)$ & 0.968 & 0.934 \\
\hline \multicolumn{7}{|l|}{$\mathrm{HbAIc}(\%)$} \\
\hline Baseline & $7.08 \pm 1.38$ & 7.09 (7.7I to 7.47$)$ & $7.26 \pm 1.46$ & 7.25 (6.89 to 7.62$)$ & 0.536 & 0.533 \\
\hline 4 weeks & $6.90 \pm 1.42$ & 6.91 (6.57 to 7.25$)$ & $6.89 \pm 1.05$ & $6.88(6.55$ to 7.21$)$ & 0.995 & 0.904 \\
\hline Change from baseline & $-0.19(-0.59$ to 0.21$)$ & $-0.18(-0.60$ to 0.24$)$ & $-0.36(-0.78$ to 0.05$)$ & $-0.37(-0.78$ to 0.03$)$ & 0.548 & 0.508 \\
\hline \multicolumn{7}{|l|}{$\mathrm{GA}^{\mathrm{b}}(\%)$} \\
\hline Baseline & $18.54 \pm 5.13$ & 18.37 (I7.09 to 19.63) & $18.37 \pm 4.54$ & I8.53 (17.3I to |9.76) & 0.861 & 0.853 \\
\hline 4 weeks & $17.52 \pm 4.47$ & 17.35 (16.19 to I8.5I) & $17.32 \pm 4.19$ & I7.48 (I6.37 to 18.60$)$ & 0.813 & 0.870 \\
\hline Change from baseline & $-1.02(-1.59$ to -0.44$)$ & $-0.57(-1.06$ to -0.08$)$ & $-1.05(-1.57$ to -0.54$)$ & $-0.54(-1.02$ to -0.07$)$ & 0.927 & 0.934 \\
\hline \multicolumn{7}{|l|}{$\mathrm{FINS}^{\mathrm{b}}(\mathrm{mU} / \mathrm{L})$} \\
\hline Baseline & $12.83 \pm 12.54$ & I3.27 (10.64 to I5.89) & $10.52 \pm 5.57$ & I0.1I (7.59 to 12.64) & 0.218 & 0.092 \\
\hline 4 weeks & $|1.7| \pm 10.75$ & 11.84 (9.64 to II.03) & $9.62 \pm 4.20$ & 9.50 (7.37 to II.64) & 0.198 & 0.137 \\
\hline Change from baseline & $-1.12(-3.76$ to 1.53$)$ & $-1.42(-3.30$ to 0.46$)$ & $-0.79(-1.87$ to 0.30$)$ & $-0.50(-2.32$ to 1.33$)$ & 0.814 & 0.490 \\
\hline \multicolumn{7}{|l|}{ hs-CRPb (pg/mL) } \\
\hline Baseline & $1.63 \pm 2.26$ & $1.72(1.13$ to 2.30$)$ & $1.58 \pm 1.98$ & I.5I (0.95 to $2.0 \mathrm{I})$ & 0.910 & 0.617 \\
\hline 4 weeks & $1.34 \pm 1.62$ & 1.43 (0.34 to 2.52$)$ & $2.29 \pm 5.17$ & 2.21 ( 1.16 to 3.26$)$ & 0.215 & 0.315 \\
\hline Change from baseline & $-0.29(-0.85$ to 0.27$)$ & $-0.28(-1.27$ to 0.70$)$ & $0.70(-0.48$ to 1.89$)$ & $0.70(-0.24$ to 1.65$)$ & 0.143 & 0.158 \\
\hline \multicolumn{7}{|l|}{ TNF- $\alpha^{\mathrm{b}}(\mathrm{pg} / \mathrm{mL})$} \\
\hline Baseline & $7.12 \pm 1.50$ & 7.11 (6.57 to 7.65$)$ & $7.37 \pm 2.20$ & 7.39 (6.87 to 7.90$)$ & 0.508 & 0.465 \\
\hline 4 weeks & $12.76 \pm 10.47$ & I2.74 (|0.66 to |4.82) & $7.02 \pm 2.20$ & 7.04 (5.04 to 9.05$)$ & $<0.01$ & $<0.01$ \\
\hline Change from baseline & 5.64 (2.70 to 8.57$)$ & 5.63 (3.56 to 7.70$)$ & $-0.35(-0.89$ to 0.20$)$ & $-0.34(-2.33$ to 1.65$)$ & $<0.01$ & $<0.01$ \\
\hline \multicolumn{7}{|l|}{ IL-6 ${ }^{\mathrm{b}}(\mathrm{pg} / \mathrm{mL})$} \\
\hline Baseline & $2.11 \pm 0.26$ & 2.13 (1.96 to 2.30$)$ & $2.39 \pm 0.8 \mathrm{I}$ & $2.38(2.21$ to 2.54$)$ & 0.018 & 0.041 \\
\hline 4 weeks & $3.09 \pm 1.92$ & 3.10 (2.68 to 3.52$)$ & $2.53 \pm 0.95$ & 2.52 (2.12 to 2.92$)$ & 0.065 & 0.051 \\
\hline Change from baseline & 0.98 (0.44 to I.52) & 0.98 (0.58 to I.38) & $0.14(-0.05$ to 0.33$)$ & $0.14(-0.24$ to 0.53$)$ & 0.005 & 0.004 \\
\hline
\end{tabular}

Notes: Continuous variables were expressed as mean ( $95 \%$ confidence intervals), and the crude $p$-value was evaluated by the independent $t$-test to show the difference between groups. The adjusted $p$-value was analyzed using the ANCOVA (generalized linear model) test. The covariates included: age and gender for weight and BMI; bgender, age, history of diabetes and baseline BMI for FBG, HbAIc, GA, FINS, hs-CRP, TNF- $\alpha$ and IL-6. $p<0.05$ indicates that the difference between groups is statistically significant, and $0.05<p<0.1$ shows a trend of the difference to be statistically significant.

Abbreviations: BMI, body mass index; EABCF, extruded adzuki bean convenient food; FBG, fasting blood glucose; FINS, fasting insulin; GA, glycated albumin; $\mathrm{HbAlc}$, glycosylated hemoglobin; hs-CRP, high sensitive C reactive protein; LGI, low glycemic index; TNF- $\alpha$, tumor necrosis factor alpha.

of the study, and therefore, the data from the remaining 88 subjects were incorporated into the final subgroup data analysis (44 subjects for each group). This study showed that the patients in the EABCF group exhibited overall compliance with the assigned diet (Table 6). The feedback from the subjects indicated that the taste of the intervention food was generally acceptable and that its characteristics of convenience were appreciated. Throughout the trial, there were no adverse events. Given that the weight of the patients in the intervention group did not obviously decrease, the EABCF appears to be well tolerated by the subjects.
The Chinese Guidelines for Nutritional Treatment for Diabetes (2013) ${ }^{13}$ advise diabetics to follow a balanced diet; dietary intake of total energy should be consistent with weight management goals, including $45 \%$ to $60 \%$ from carbohydrates, $25 \%$ to $35 \%$ from proteins and $15 \%$ to $20 \%$ from fats. The guidelines suggest that an increase in plant protein intake is more beneficial to lowering blood lipids than a higher intake of animal-derived proteins. The recommended dietary fiber intake of diabetic patients should match or exceed the recommended intake of non-diabetic people, with a specific recommended amount of 25-30 g daily. 
Table 5 The subgroup analysis of the homeostasis model assessment (HOMA) based on the different serum insulin levels at baseline for the participants who were not treated with exogenous insulin

\begin{tabular}{|c|c|c|c|}
\hline $\begin{array}{l}\text { Subgroup I } \\
\text { FINS } \geq 17.2 \mathrm{mU} / \mathrm{L}\end{array}$ & $\begin{array}{l}\text { LGI group } \\
(n=4)\end{array}$ & $\begin{array}{l}\text { EABCF group } \\
(n=4)\end{array}$ & $p$-value \\
\hline \multicolumn{4}{|l|}{ FINS (mU/L) } \\
\hline Baseline & $29.52 \pm 17.69$ & $17.91 \pm 0.47$ & 0.281 \\
\hline 4 weeks & $24.67 \pm 22.63$ & $15.58 \pm 4.58$ & 0.485 \\
\hline Change from baseline & $-4.85(-47.73$ to 38.03$)$ & $-2.34(-10.36$ to 5.69$)$ & 0.860 \\
\hline \multicolumn{4}{|l|}{ Ln FINS (mU/L) } \\
\hline Baseline & $3.27(2.40$ to 4.13$)$ & 2.89 (2.84 to 2.93$)$ & 0.258 \\
\hline 4 weeks & 2.92 ( 1.57 to 4.27$)$ & 2.71 (2.26 to 3.17$)$ & 0.660 \\
\hline Change from baseline & $-0.34(-1.61$ to 0.92$)$ & -0.17 (-0.67 to 0.32$)$ & 0.698 \\
\hline \multicolumn{4}{|l|}{ Ln HOMA-IR $\left(\mu U \times \mathrm{mol} / \mathrm{L}^{2}\right)$} \\
\hline Baseline & 2.19 (1.05 to 3.33$)$ & 1.75 ( 1.47 to 2.02$)$ & 0.308 \\
\hline 4 weeks & $1.7 \mathrm{I}(0.10$ to $3.3 \mathrm{I})$ & $1.57(0.97$ to 2.16$)$ & 0.804 \\
\hline Change from baseline & $-0.48(-1.73$ to 0.76$)$ & $-0.18(-0.95$ to 0.59$)$ & 0.534 \\
\hline \multicolumn{4}{|l|}{ Ln HOMA-IS (L2/ $\mu \mathrm{U} \times \mathrm{mol})$} \\
\hline Baseline & $-2.19(-3.33$ to -1.05$)$ & $-1.75(-2.02$ to -1.47$)$ & 0.308 \\
\hline 4 weeks & $-1.71(-3.31$ to -0.10$)$ & $-1.57(-2.16$ to -0.97$)$ & 0.804 \\
\hline Change from baseline & $0.48(-0.76$ to 1.73$)$ & $0.18(-0.59$ to 0.95$)$ & 0.534 \\
\hline \multicolumn{4}{|l|}{ Ln HOMA- $\beta$ (\%) } \\
\hline Baseline & 4.88 (4.04 to $5.7 I)$ & 4.59 (4.09 to 5.08$)$ & 0.383 \\
\hline 4 weeks & 4.79 (3.90 to 5.68$)$ & 4.43 (4.06 to 4.80$)$ & 0.281 \\
\hline Change from baseline & $-0.09(-1.38$ to 1.20$)$ & $-0.16(-0.35$ to 0.03$)$ & 0.868 \\
\hline Subgroup 2 & LGI group & EABCF group & $p$-value \\
\hline $5.2 \leq$ FISN $<17.2 \mathrm{mU} / \mathrm{L}$ & $(n=33)$ & $(n=30)$ & \\
\hline \multicolumn{4}{|l|}{ FINS (mU/L) } \\
\hline Baseline & $9.89 \pm 3.17$ & $10.31 \pm 3.20$ & 0.598 \\
\hline 4 weeks & $9.19 \pm 3.34$ & $8.60 \pm 3.10$ & 0.474 \\
\hline Change from baseline & $-0.70(-1.66$ to 0.26$)$ & $-1.71(-2.56$ to -0.86$)$ & 0.115 \\
\hline \multicolumn{4}{|l|}{ Ln FINS (mU/L) } \\
\hline Baseline & 2.24 (2.12 to 2.36$)$ & 2.28 (2.16 to $2.4 \mathrm{I})$ & 0.582 \\
\hline 4 weeks & 2.15 (2.0I to 2.29$)$ & 2.08 (1.92 to 2.23$)$ & 0.491 \\
\hline Change from baseline & $-0.09(-0.20$ to 0.02$)$ & $-0.21(-0.32$ to -0.09$)$ & 0.126 \\
\hline \multicolumn{4}{|l|}{ Ln HOMA-IR $\left(\mu \mathrm{U} \times \mathrm{mol} / \mathrm{L}^{2}\right)$} \\
\hline Baseline & 1.22 (1.05 to 1.39$)$ & 1.30 (I.I6 to I.44) & 0.487 \\
\hline 4 weeks & $1.09(0.92$ to 1.26$)$ & I.05 (0.87 to I.23) & 0.723 \\
\hline Change from baseline & $-0.13(-0.26$ to 0$)$ & $-0.25(-0.4 \mid$ to -0.09$)$ & 0.222 \\
\hline \multicolumn{4}{|l|}{ 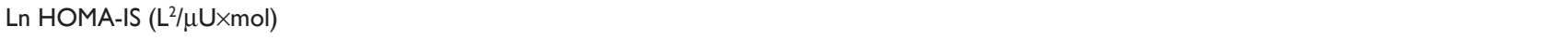 } \\
\hline Baseline & $-1.22(-1.39$ to -1.05$)$ & $-1.30(-1.44$ to -1.16$)$ & 0.487 \\
\hline 4 weeks & $-1.09(-1.26$ to -0.92$)$ & $-1.05(-1.23$ to -0.87$)$ & 0.723 \\
\hline Change from baseline & 0.13 (0 to 0.26$)$ & 0.25 (0.09 to $0.4 \mathrm{I})$ & 0.222 \\
\hline \multicolumn{4}{|l|}{ Ln HOMA- $\beta$ (\%) } \\
\hline Baseline & 3.74 (3.58 to 3.89$)$ & $3.72(3.53$ to 3.90$)$ & 0.855 \\
\hline 4 weeks & 3.72 (3.53 to 3.92$)$ & $3.60(3.40$ to 3.80$)$ & 0.367 \\
\hline Change from baseline & $-0.02(-0.15$ to 0.12$)$ & $-0.12(-0.22$ to -0.02$)$ & 0.238 \\
\hline Subgroup 3 & LGI group & EABCF group & $p$-value \\
\hline FINS $<5.2 \mathrm{mU} / \mathrm{L}$ & $(n=7)$ & $(n=10)$ & \\
\hline \multicolumn{4}{|l|}{ FINS (mU/L) } \\
\hline Baseline & $4.19 \pm 0.74$ & $4.30 \pm 0.86$ & 0.784 \\
\hline 4 weeks & $4.5 I \pm I .5 I$ & $7.27 \pm 4.19$ & 0.079 \\
\hline Change from baseline & $0.32(-1.28$ to 1.91$)$ & $2.97(0.15$ to 5.80$)$ & 0.118 \\
\hline \multicolumn{4}{|l|}{ Ln FINS (mU/L) } \\
\hline Baseline & I.42 (1.25 to I.59) & 1.44 (I.27 to 1.60$)$ & $0.86 I$ \\
\hline 4 weeks & 1.46 ( 1.16 to 1.76$)$ & 1.86 ( 1.49 to 2.22$)$ & 0.091 \\
\hline Change from baseline & $0.04(-0.31$ to 0.40$)$ & $0.42(0.10$ to 0.74$)$ & 0.092 \\
\hline
\end{tabular}


Table 5 (Continued)

\begin{tabular}{|c|c|c|c|}
\hline $\begin{array}{l}\text { Subgroup } 3 \\
\text { FINS }<5.2 \mathrm{mU} / \mathrm{L}\end{array}$ & $\begin{array}{l}\text { LGI group } \\
(n=7)\end{array}$ & $\begin{array}{l}\text { EABCF group } \\
(n=10)\end{array}$ & $p$-valu \\
\hline \multicolumn{4}{|l|}{ Ln HOMA-IR $\left(\mu \mathrm{U} \times \mathrm{mol} / \mathrm{L}^{2}\right)$} \\
\hline Baseline & $0.49(0.18$ to 0.80$)$ & $0.49(0.17$ to 0.80$)$ & 0.982 \\
\hline 4 weeks & $0.48(0$ to 0.97$)$ & $0.93(0.4 \mathrm{I}$ to $\mathrm{I} .45)$ & 0.185 \\
\hline Change from baseline & $-0.01(-0.47$ to 0.46$)$ & 0.45 (0.05 to 0.84$)$ & 0.107 \\
\hline \multicolumn{4}{|l|}{ Ln HOMA-IS (L2/ $\mu \mathrm{U} \times \mathrm{mol})$} \\
\hline Baseline & $-0.49(-0.80$ to -0.18$)$ & $-0.49(-0.80$ to -0.17$)$ & 0.982 \\
\hline 4 weeks & $-0.48(-0.97$ to 0$)$ & $-0.93(-1.45$ to $-0.4 I)$ & 0.185 \\
\hline Change from baseline & $0.01(-0.46$ to 0.47$)$ & $-0.45(-0.84$ to -0.05$)$ & 0.107 \\
\hline \multicolumn{4}{|l|}{ Ln HOMA- $\beta$ (\%) } \\
\hline Baseline & $2.76(2.3 \mathrm{I}$ to 3.22$)$ & $2.82(2.54$ to 3.10$)$ & 0.780 \\
\hline 4 weeks & $2.89(2.51$ to 3.26$)$ & 3.21 (2.86 to 3.55$)$ & 0.179 \\
\hline Change from baseline & $0.13(-0.14$ to 0.39$)$ & $0.38(0.13$ to 0.63$)$ & 0.133 \\
\hline
\end{tabular}

Notes: Continuous variables were expressed as mean ( $95 \%$ confidence intervals), and $p$-values were calculated by the independent $t$-test to show the difference between groups; $p<0.05$ indicates that the difference between groups is statistically significant, and $0.05<p<0.1$ shows a trend toward statistical significance. Ln is the natural logarithm. Abbreviations: EABCF, extruded adzuki bean convenient food; FBG, fasting blood glucose; FINS, fasting insulin; LGI, low glycemic index.

In this study, after the 4-week intervention, the dietary patterns of all participants were optimized (Table 3). The change in dietary patterns improved among the subjects who consumed the convenient food to a greater extent compared to those who followed the traditional LGI foods. In the EABCF group, the average carbohydrate energy ratio was $<60 \%(59 \%)$, the average protein to energy ratio $(17.34 \%)$ was significantly higher than that in the LGI group (adjusted $p=0.001$ ), and the average fat energy supply ratio was slightly lower than that in the LGI group and was lower than $25 \%$ in both groups. The 4 -week intervention also prevented a sharp decrease in fiber intake in the EABCF group compared to that of the control group. However, at the end, the dietary fiber intake in both groups was still far from the recommended amount.

The contents of carbohydrates, protein and dietary fiber in the red adzuki bean is $55 \%-60 \%, 18 \%-23 \%$ and $7 \%-19 \%$, respectively. ${ }^{19}$ Compared to white rice and white flour, the red adzuki bean has higher protein and dietary fiber content and a lower carbohydrate content. Furthermore, the carbohydrates in the red bean are tightly wrapped within dietary fiber and protein; therefore, the digestion rate of the starch in the red bean is low. Given this special structure, the red adzuki bean reduces the postprandial blood sugar response.

Table 6 Intervention consumption statistics

\begin{tabular}{llll}
\hline Consumption & Vermicelli & $\begin{array}{l}\text { Instant } \\
\text { powder }\end{array}$ & $\begin{array}{l}\text { Hard } \\
\text { candy }\end{array}$ \\
\hline Minimum daily recommendation $(\mathrm{g})$ & $50-75$ & 48 & 12 \\
Total during 4 weeks $(\mathrm{kg})$ & 145.195 & 84.346 & 19.904 \\
Per capita during 4 weeks $(\mathrm{kg})$ & 2.593 & 1.506 & 0.355 \\
Per capita daily $(\mathrm{g})$ & 92.6 & 53.8 & 12.7 \\
\hline
\end{tabular}

In this study, the extrusion process increased the proportion of protein and soluble dietary fiber in the red adzuki bean, resulting in better taste and improved convenience for cooking compared to other traditional coarse grains. ${ }^{19}$ The improvement of adzuki bean composition by extrusion technology may be the reason for the optimization of dietary patterns of subjects in the intervention group.

The adzuki bean, a recommended staple food for diabetic patients, has attracted increasing attention due to its biological characteristics. Originally, the adzuki bean was identified as a staple food for diabetics because it is a type of legume that is high in protein and fiber and low in carbohydrates. Compared to grains, legumes contain more amylose and sticky dietary fiber. As a result, the starch granules of legumes have a unique structure, and the hydrolysis of the starch in the small intestine is relatively slow. Thus, the postprandial glycemic response is delayed. Studies have found that the mechanism by which red bean can fight hyperglycemia may be related to the effects of adzuki bean protein and phenolic compounds. ${ }^{4,20}$ In addition, animal experiments have confirmed that the red adzuki bean has the strongest glucosidase inhibition among 16 kinds of dry beans. ${ }^{20}$ In vitro experiments have revealed that the capacity for glycosidase inhibition of red adzuki bean was increased by more than 3 times after the extrusion process. ${ }^{21}$ In addition, this experiment also proved that the extruded red bean protein and polysaccharides play a role in $\alpha$-glucosidase inhibition. ${ }^{21}$ This research further clarified that the effective components are vitexin and isovitexin, which are separated during the extrusion process. ${ }^{21} \alpha$-Glucosidase is a key enzyme in the small intestine epithelium that digests carbohydrates and increases postprandial blood sugar. Increased $\alpha$-glucosidase 
activity is one of the earliest metabolic abnormalities in T2DM patients. ${ }^{3,22} \alpha$-Glucosidase inhibitors slow digestion and absorption of carbohydrates, which, in turn, reduces the postprandial glucose. ${ }^{23}$ In the current study, due to the limited experimental conditions, the plasma postprandial glucose throughout the day could not be measured. Furthermore, there are unavoidable errors in the self-measured postprandial finger-stick glucose levels; therefore, these data were not included in this analysis. Instead, the researchers selected $\mathrm{HbA} 1 \mathrm{c}$ and GA as the target indices to monitor recent glycemic control. The results of this trial showed that the GA and HbA1c levels of both groups decreased after the 4-week intervention, but the differences did not reach statistical significance (adjusted $p>0.05$ ). This finding suggests that, compared to the traditional LGI diabetic diet, the EABCF did not lead to better glycemic control, although the EABCF played a role in reducing fasting blood sugar and maintaining blood sugar stability. The reason for this may be that the glycemic index of red bean is not significantly lower than that of other coarse grains.

With an increasing number of studies investigating the pathogenesis of T2DM, there has been an increasing focus on the relationship of the inflammatory status with insulin resistance and pancreatic beta cell dysfunction in T2DM. Inflammatory factors associated with type 2 diabetes are mainly $\mathrm{C}$ reactive protein (CRP), TNF- $\alpha$, interleukin-6 (IL-6), plasminogen activator inhibitor 1 (PAI-1) and other factors such as fat sialic acid and endothelial adhesion molecule. ${ }^{24}$ TNF- $\alpha$ is a cytokine mainly produced by monocytes and macrophages and has a wide range of biological activity. It can induce the synthesis of IL-1, IL-6 and CRP. It was the first inflammatory factor known to be involved in insulin resistance and T2DM. ${ }^{25}$ The main mechanisms include the following: 1) direct damage to the DNA of pancreatic beta cells; 2) induction of nitric oxide, which can restrain the feedback regulation for insulin secretion triggered by blood glucose; 3) blockade of insulin signal transduction via inhibition of the phosphorylation of insulin receptors and substrates; 4) inhibition of the transcription of the glucose transporter 4 (GLUT4) gene and acceleration of degradation of mRNA; and 5) accumulation of TNF- $\alpha$, resulting in the positive feedback loop of slight inflammation, which further increases insulin resistance. ${ }^{26}$ IL-6 mediates acute inflammatory reactions through the synthesis of CRP in the liver, which can block the insulin signaling cascade and thus cause dysfunction of the phosphorylation of insulin receptors and substrates induced by insulin. Such a series of inflammatory reactions eventually result in abnormal glucose metabolism. ${ }^{26}$ Commonly used hypoglycemic agents, such as metformin, rosiglitazone maleate, pioglitazone, and exogenous insulin, all have dual effects on lowering blood glucose and improving inflammation. ${ }^{26-28}$ Therefore, they play additional beneficial roles in the treatment of diabetes and the prevention of complications in addition to their hypoglycemic effect. ${ }^{27-29}$ However, there have been few studies on the association between dietary intervention and inflammatory factors associated with T2DM. Zhou et al ${ }^{30}$ conducted a clinical trial in which hypoglycemia index (LGI) and low glycemic load (LGL) diet interventions were combined and showed that diet control in T2DM patients can reduce FBG, TNF- $\alpha$, CRP and IL-6 levels simultaneously. Our study also found that the EABCF intervention group had reduced inflammation compared to the LGI control group. The TNF- $\alpha$ level decreased in the EABCF group and was significantly lower than that in the LGI group (adjusted $p<0.01$ ). Compared to baseline, IL-6 levels increased in both groups; the level of increase in the LGI group was significantly higher than that in the intervention group (adjusted $p=0.004$ ). At the end of the study, the IL-6 level in the EABCF group trended toward being statistically significantly lower than that in the LGI group (adjusted $0.05<p=0.051<0.1$ ) (Table 4 ). The mechanism by which red adzuki bean alleviates inflammation may be related to the high level of flavonoids in red adzuki bean. Therefore, it is reasonable to infer that the extruded red adzuki bean may also have other beneficial effects also observed with common antidiabetic agents, such as improving lipid metabolism and preventing diabetic complications.

To determine the relationship between the hypoglycemic and anti-inflammatory effects of the extruded red adzuki bean convenient food, HOMA subgroup analysis was carried out after patients with exogenous insulin use were excluded. The results showed that diet control had a bidirectional regulation on insulin secretion. Secretion of FINS was inhibited in the insulin over- and normal-secretion groups, while insulin secretion was promoted in the inhibited-secretion group (Table 5). However, compared to the LGI group, there was no remarkable advantage of the EABCF in improving insulin resistance or pancreatic beta cell function. In contrast, another clinical trial conducted by one of the researchers of this study focusing on tartary buckwheat (a common edible coarse grain in China) indicated that replacing white rice or flour with tartary buckwheat can help improve insulin resistance in T2DM patients. ${ }^{31}$ The reason for the opposing results may be that the control group in this trial consumed LGI staple foods rather than white rice or flour. 


\section{Conclusion}

This clinical study illustrated that extruded red adzuki bean convenient food can be used to help patients with T2DM optimize dietary patterns and increase protein intake while reducing total energy intake. The EABCF was easy to cook and tasted good, leading to patient compliance. Such a convenient diet has similar effects on maintaining glucose homeostasis as the traditional LGI diabetic diet. Furthermore, it can also improve the inflammatory state of T2DM. However, this advantage was not statistically significant. This may be related to the limitation of the study design, such as the small sample size and short intervention duration. Moreover, confounding factors, including history and course of disease and concomitant medications, may have interfered with the results. Further studies with larger sample sizes, longer intervention periods and stronger homogeneity within the study population are needed to explore the association between improvement in glycemic control and inflammation and to delineate additional beneficial effects of the extruded red adzuki bean convenient food on T2DM.

\section{Acknowledgments}

First of all, we express our sincere thanks to Yimin Qu, Yuanyuan Bao and Rui Li from Peking Union Medical College Hospital for their help on the distribution and arrangement of the questionnaires as well as the data entry and analysis. Secondly, Xinyao Zhang needs special thanks for his help in the test of IL-6 and TNF- $\alpha$. Finally, Kang Li, Tong Xing, and Huikun Qin, colleagues from the Nutritional Department of Pinggu Hospital of Traditional Chinese Medicine, should be sincerely thanked for their kind work on the collection and management of the clinical participants.

This study was supported by the earmarked fund for the Modern Agro-Industry Technology Research System (nycytx018) and the Sci \& Tech Innovation Program of CAAS.

\section{Disclosure}

The authors report no conflicts of interest in this work.

\section{References}

1. Yao Y, Chen F, Wang M, Wang J, Ren G. Antidiabetic activity of Mung bean extracts in diabetic KK-Ay mice. Journal of Agricultural and Food Chemistry. 2008;56(19):8869-8873.

2. Yang YX, Wang GX, Pan XC. China Food Composition (2nd Eidition). Beijing: Peking University Medical Press; 2009.

3. Yao Y, Ren G. Suppressive effect of extruded adzuki beans (Vigna angularis) on hyperglycemia after sucrose loading in rats. Industrial Crops \& Products. 2014;52(1):228-232.

4. Yao Y, Cheng X, Ren G. Alpha-Glucosidase inhibitory activity of proteinrich extracts from extruded adzuki bean in diabetic KK-Ay mice. Food \& Function. 2014;5(5):966-971.

5. Jin C. Red bean cultivation techniques. Nong Min Zhi Fu Zhi You. 2014;(24):186.
6. Fontvieille AM, Rizkalla SW, Penfornis A, Acosta M, Bornet FR, Slama G. The use of low glycaemic index foods improves metabolic control of diabetic patients over five weeks. Diabetic medicine: A Journal of the British Diabetic Association. 1992;9(5):444-450.

7. Wei YF, Yan J, Wang HD, Guo S. Establishment of spectrophotometric method for determination of total flavonoids in Adzuki Bean and determination of medicinal substances in different habitats of China. Shi Zhen Guo Yi Guo Yao. 2010;21(11):2729-2731.

8. Santangelo C, Vari R, Scazzocchio B, Di Benedetto R, Filesi C, Masella R. Polyphenols, intracellular signalling and inflammation. Annali dell'Istituto superiore di sanita. 2007;43(4):394-405.

9. Ye QJ, Yang GM, Zhang QK, Xie L. The new application and progress of extrusion technology. Journal of Food Safety and Quality. 2013; 5:1329-1334.

10. Diagnosis and classification of diabetes mellitus. Diabetes Care. 2010; 33 Suppl 1:S62-S69.

11. Wang T. Prevalence, control and risk factors of diabetes in Chinese adults. Shanghai: Shanghai Jiao Tong University, Shanghai Jiao Tong University; 2014.

12. The Chinese Nutrition Society. Dietary guidelines for Chinese residents Beijing: People's Medical Publishing House; 2016.

13. Chinese Medical Association Diabetes Branch, Chinese Physicians Association Nutrition Physician Professional Committee. Chinese Guidelines for Nutritional Treatment for Diabetes. Diabetes World. 2013;(7):289-307.

14. Xue $\mathrm{H}$. Incidence of diabetes and association between abdominal obesity and risk of diabetes among Chinese adults: a prospective cohort study. Beijing: Fuwai Hospital of Cardiovascular Disease, Peking Union Medical College; 2014.

15. Chobanian AV, Bakris GL, Black HR, et al. The Seventh Report of the Joint National Committee on Prevention, Detection, Evaluation, and Treatment of High Blood Pressure: the JNC 7 report. JAMA. 2003;289(19):2560-2572.

16. Third Report of the National Cholesterol Education Program (NCEP) Expert Panel on Detection, Evaluation, and Treatment of High Blood Cholesterol in Adults (Adult Treatment Panel III) final report. Circulation. 2002;106(25):3143-3421.

17. Grundy SM, Cleeman JI, Merz CN, et al. Implications of recent clinical trials for the National Cholesterol Education Program Adult Treatment Panel III guidelines. Circulation. 2004;110(2):227-239.

18. Chinese Working Group on Obesity. Guidelines for the prevention and control of overweight and obesity in adults in China. Journal of Nutrition. 2004;(24):1-4.

19. Han T, Sun XJ, Li LP, Jin W. Preliminary study on Extraction and separation of protein and starch from adzuki bean. Food Technology. 1997;(05): 43-45.

20. Yao Y, Cheng X, Wang L, Wang S, Ren G. Biological potential of sixteen legumes in China. International Journal of Molecular Sciences. 2011;12(10):7048-7058.

21. Yao Y, Cheng X, Wang L, Wang S, Ren G. A determination of potential alpha-glucosidase inhibitors from Azuki Beans (Vigna angularis). International Journal of Molecular Sciences. 2011;12(10):6445-6451.

22. Krentz AJ, Bailey CJ. Oral antidiabetic agents: current role in type 2 diabetes mellitus. Drugs. 2005;65(3):385-411.

23. Lebovitz HE. Postprandial hyperglycaemic state: importance and consequences. Diabetes Research and Clinical Practice. 1998;40 Suppl:S27-S28.

24. Abete I, Parra D, Martinez JA. Energy-restricted diets based on a distinct food selection affecting the glycemic index induce different weight loss and oxidative response. Clinical Nutrition (Edinburgh, Scotland). 2008; 27(4):545-551.

25. Honkanen J, Nieminen JK, Gao R, et al. IL-17 immunity in human type 1 diabetes. Journal of immunology (Baltimore, Md.: 1950). 2010; 185(3):1959-1967.

26. Shi QR, Tian JW, Wang L. Advances in treatment of type 2 diabetes mellitus with inflammation. Journal of Practical Medicine. 2007;15:2289-2291.

27. Dandona P, Mohanty P, Chaudhuri A, Garg R, Aljada A. Insulin infusion in acute illness. The Journal of Clinical Investigation. 2005; 115(8):2069-2072. 
28. Satoh N, Ogawa Y, Usui T, et al. Antiatherogenic effect of pioglitazone in type 2 diabetic patients irrespective of the responsiveness to its antidiabetic effect. Diabetes Care. 2003;26(9):2493-2499.

29. Huang B, Luo L, Han W, Xie X, Luo X, Wei D. The effects of rosiglitazone on lipid and glucose metabolism, insulin resistance and inflammatory factors in type 2 diabetic patients. Chinese Journal of Diabetes. 2006;(01):9-10.
30. Zhou W, Huang J, Xia JQ, et al. Effects of diet interventions on glycemic control and cytokines changes in patients with type 2 diabetes mellitus. China Journal of Modern Medicine. 2013;01:52-56.

31. Qiu J, Liu Y, Yue Y, Qin Y, Li Z. Dietary tartary buckwheat intake attenuates insulin resistance and improves lipid profiles in patients with type 2 diabetes: a randomized controlled trial. Nutrition research (New York, N.Y.). 2016;36(12):1392-1401.

\section{Publish your work in this journal}

Therapeutics and Clinical Risk Management is an international, peerreviewed journal of clinical therapeutics and risk management, focusing on concise rapid reporting of clinical studies in all therapeutic areas, outcomes, safety, and programs for the effective, safe, and sustained use of medicines. This journal is indexed on PubMed Central, CAS,
EMBase, Scopus and the Elsevier Bibliographic databases. The manuscript management system is completely online and includes a very quick and fair peer-review system, which is all easy to use. Visit http://www.dovepress.com/testimonials.php to read real quotes from published authors.

Submit your manuscript here: http://www.dovepress.com/therapeutics-and-clinical-risk-management-journal 